\title{
Identification of a New Resistance Gene to a Chinese Blast Fungus Isolate in the Japanese Rice Cultivar Aichi Asahi
}

\author{
Nagao Hayashi, Ikuo Ando, and Tokio Imbe
}

First and second authors: Department of Plant Protection and Department of Crop Breeding, National Agriculture Research Center, Kannondai 3-3-1, Tsukuba 305-8666, Japan; and third author: International Rice Research Institute, P.O. Box 933, Manila, Philippines.

Current address of N. Hayashi: Aichi-ken Agriculture Research Center, Mountainous Region Agricultural Research Institute, Inabu, Aichi 441-2513, Japan.

Current address of I. Ando: Agriculture, Forestry and Fisheries Research Council Secretariat, Ministry of Agriculture, Forestry and Fisheries, 1-2-1 Kasumigaseki, Chiyoda-ku, Tokyo 100, Japan.

Accepted for publication 23 April 1998.

\begin{abstract}
Hayashi, N., Ando, I., and Imbe, T. 1998. Identification of a new resistance gene to a Chinese blast fungus isolate in the Japanese rice cultivar Aichi Asahi. Phytopathology 88:822-827.

Genetic analysis of the rice cultivar Aichi Asahi and some other Japanese cultivars for the high resistance to the blast fungus isolate CHNOS58-3-1 from China was performed. All the Japanese differential cultivars were resistant to the isolate except for 'Pi No. 4', which showed moderate

To identify the gene in other Japanese differential cultivars, AK lines, which were derived from a cross of 'Aichi Asahi' $\times$ 'K59' and assumed to harbor no known genes except for the new one, were used for the allelism tests. The new, completely dominant resistance gene was detected in 14 differential cultivars, but not in 'Pi No. 4', 'Yashiro-mochi', and 'K1', and was designated as $P i 19(t)$. Pi19(t) was allelic or closely linked to $P_{i t a^{2}}$ on chromosome 12. Pi19(t) was extensively distributed among Japanese traditional local cultivars.
\end{abstract} resistance. Analysis of the $\mathrm{F}_{2}$ population of a cross of the susceptible cultivar Reiho and the resistant cultivar Aichi Asahi indicated that the resistance of 'Aichi Asahi' to the isolate was conferred by one dominant gene.
Additional keywords: japonica, Oryza sativa, Pyricularia oryzae.
Rice blast, caused by Pyricularia grisea (Cooke) Sacc. (25), is one of the most widespread and serious diseases of rice (Oryza sativa L.). Therefore, breeding and genetic studies on rice blast resistance have been performed systematically in Japan. The most comprehensive and systematic studies on pathotype-specific blast resistance have been conducted by Kiyosawa and coworkers (911,13-16,20,31) in Japan. In these studies, 12 resistance genes have been identified. Yokoo and Kiyosawa (32) identified the $\mathrm{Piz}^{t}$ gene in 'Toride 1', which was introduced from the Indian cultivar TKM1. Imbe and Matsumoto (4) identified the Pish gene in Japanese cultivars using a new race of blast fungus isolated from the resistant cultivar Reiho harboring the $P i t a^{2}$ gene. In contrast, genetic studies in the tropics have lagged behind because of the presence of a large number of unidentified resistance genes in tropical rice cultivars. Mackill and Bonman (23) identified Pil(t), Pi2(t), Pi3(t), $\mathrm{Pi}^{a}(t)$, and Pi4 ${ }^{b}(t)$. Wang et al. (29) identified and mapped Pi5(t) and $P i 7(t)$, which were derived from the cultivar Moroberekan. Pan et al. (24) identified and mapped Pi8, which was derived from the cultivar Kasalath. Recently, Inukai et al. (5) and Kinoshita et al. (7) determined the relationships between the blast resistance genes in the near-isogenic lines of 'CO39' and Kiyosawa's differentials developed in Japan. They found that Pil(t) and Pi3(t) were new loci, and $P i 2(t)$ was renamed $P i z^{5}$ because it was allelic to the Piz locus. They also found that $P i 4^{a}(t)$ and $P i 4^{b}(t)$ were identical to Pita.

Although all the major genes for blast resistance may have already been identified in the combinations of Japanese rice cultivars and Japanese blast isolates (18), it still may be possible to identify new resistance genes in a Japanese cultivar using foreign

Corresponding author: N. Hayashi; E-mail address: lalalu@mr-agri-rc.pref.aichi.jp

Publication no. P-1998-0622-02R

(C) 1998 The American Phytopathological Society isolates. We observed several blast isolates in Yunnan, China, that did not show any pathogenicity to any of the Japanese differential cultivars. These isolates may harbor an avirulence gene corresponding to a resistance gene that has not been determined in Japan. The objective of this study was to clarify the mode of inheritance of blast resistance in Japanese differential cultivars to isolate CHNOS58-3-1, one of the incompatible isolates of $P$. grisea.

\section{MATERIALS AND METHODS}

Plant materials. We attempted to breed a line that does not carry any of the 14 known resistance genes but is resistant to isolate CHNOS58-3-1 according to the following procedure. It is known that 'Aichi Asahi' carries only Pia, and 'K59' carries only Pit (4,15,31). 'K59' carries an additional gene, $P i k^{s}$ (N. Hayashi, unpublished data). Lines susceptible to the blast isolates Ina72 (with $A v-a$ and $A v-t$, avirulence genes assumed to correspond to resistance genes) and PH77-89-1 (with $A v-k s$ and $A v-s h$ ) were selected in the $\mathrm{F}_{3}$ and $\mathrm{F}_{4}$ generations, respectively. In the $\mathrm{F}_{5}$ generation, two highly susceptible lines, AK-1 and AK-2, lacking the Pia, Pit, and $P i k^{s}$ genes but resistant to isolate CHNOS58-3-1, were selected and used for allelism tests and genetic analysis.

AK-1 or AK-2 was crossed with the 15 Japanese differentials and with 'Reiho'. The transmission of the new resistance gene to $\mathrm{F}_{1}$ plants was confirmed by inoculation with appropriate pathogens to which self-pollinated plants were susceptible. The $F_{2}$ populations were produced by self-pollination of individual $F_{1}$ plants by bagging in a greenhouse in the winter season from 1994 to 1995 . To determine whether the cultivars carrying the resistance allele at the Pita locus harbored the new gene, an additional 36 cultivars with the Pita or Pita ${ }^{2}$ genes were inoculated with CHNOS58-3-1 and other isolates. Furthermore, 17 Japanese traditional cultivars that had been frequently used as parents for rice breeding and five 
Japanese cultivars lacking $P i k^{s}$ were tested to analyze the distribution of the new gene in Japanese rice cultivars.

Pathogen isolates. Eight isolates of $P$. grisea, CHNOS58-3-1, Ken54-20, Ina72, PH77-89-1, GFOS7-1-1, GFOS8-1-1, 3986-R2 , and 3986-R-3, were used in this study. These isolates harbored different avirulence genes corresponding to host resistance genes and indicated a host specificity as shown in Table 1. Isolate Ken54-20 was virulent to a cultivar carrying Pia, while GFOS7-1-1 was avirulent. Isolate GFOS7-1-1 was virulent to a cultivar carrying Pita $^{2}$, but Ken54-20 was avirulent. Both isolates were virulent to the AK lines with the new gene.

Isolate CHNOS58-3-1 was used for the $F_{2}$ analysis of each cross between AK-1 or AK-2 and the set of Japanese differential cultivars with the known resistance genes listed in Table 2 (17). The isolate was originally collected from lowland rice, cultivar unknown, in Jinghong, Yunnan, China, in 1992. All the Japanese differential cultivars were resistant to the isolate with lesion type 0 or 1, though the cultivar Pi No. 4 showed an intermediate resistant reaction, lesion type 2 (Table 2). However, the isolate was confirmed to be pathogenic to rice, because it was compatible to cultivars Reiho and Tadukan.

Blast isolates 3986-R-2 and 3986-R-3, which were selected from progenies of a cross between the field isolate CHNOS60-2-3 $(A v-k s, A v-s h)$ and the laboratory fertile strain 2145-R-57 $\left(A v-k s^{+}\right.$, $\left.A v-s h^{+}\right)$, were used to detect the blast resistance genes $P i k^{s}$ and Pish in the cultivars, respectively. Isolate $2145-\mathrm{R}-57$ was selected for fertility from progenies of a cross between the field isolates CHNOS37-1-1 and CHNOS12-2-1. These field isolates, including CHNOS60-2-3, were obtained in upland rice plants in Yunnan, where most of the isolates were highly fertile (2). Other isolates were inoculated to determine each known gene in the differentials.

Inoculation methods. For the $\mathrm{F}_{2}$ or $\mathrm{F}_{3}$ analysis, 10 seeds of $\mathrm{F}_{2}$ or $\mathrm{F}_{3}$ plants were uniformly sown in each row of a plastic tray $(15 \times$ $5 \times 10 \mathrm{~cm}$ ) that was divided into two rows. About $1,000 \mathrm{~F}_{2}$ seedlings each in all 19 crosses and 20 seedlings each in $290 \mathrm{~F}_{3}$ lines from crosses between 'Reiho' and AK-1 or AK-2 were evaluated.

To produce the inoculum, the isolates were multiplied on oatmeal agar at $26^{\circ} \mathrm{C}$. After 11 to 12 days of subculturing, aerial mycelia were washed off by gentle rubbing with a water-soaked paintbrush. The colony was then exposed to near-UV light $(360 \mathrm{~nm}, 18 \mathrm{~W}$, Toshiba FL 20S BLB; Toshiba Corp., Tokyo) at $21^{\circ} \mathrm{C}$ for 3 to 4 days to induce sporulation. The mycelia were scraped and flooded with water to which Tween 20 detergent had been added at $0.01 \%$ concentration. The conidial suspension was filtered through three layers of gauze mesh and adjusted to a given concentration.

Seedlings were inoculated by spraying at the 4.5- to 4.9-leaf stages with $10 \mathrm{ml}$ per plastic tray of an aqueous spore suspension containing $1 \times 10^{5}$ to $1.5 \times 10^{5}$ spores per $\mathrm{ml}$. Inoculated seedlings were kept in a dark chamber with a moisture-saturated atmosphere at $24.5^{\circ} \mathrm{C}$ for $20 \mathrm{~h}$, and then maintained at $26.5^{\circ} \mathrm{C}$ and 70 to $80 \%$ relative humidity in a greenhouse. At 5 to 6 days after inoculation, the plants were scored for the degree of resistance to blast isolates according to the following classification: $0=$ no visible evidence of infection, $1=$ brown specks less than $0.5 \mathrm{~mm}$ in diameter, $2=$ roundish lesions smaller than the interval between thin veins or less than $1 \mathrm{~mm}$ in diameter surrounded by brown margins, $3=$ small eyespot lesions less than one and a half times the interval between thin veins or less than $1.5 \mathrm{~mm}$ in diameter surrounded by dark brown margins, 4 = intermediate-size eyespot lesions less than twice the interval between thin veins or less than $2 \mathrm{~mm}$ in diameter with necrotic gray centers and water-soaked or brown margins, and $5=$ large eyespot lesions more than twice the interval between thin veins or more than $2 \mathrm{~mm}$ in diameter. Plants were scored for the degree of resistance for comparison with the reactions of parental cultivars. Plants with infection types 0 and 1 were classified as resistant, those with types 2 and 3 were classified as intermediate, and those with types 4 and 5 were classified as susceptible.

Individual $\mathrm{F}_{2}$ populations of the crosses between 'Reiho' and $\mathrm{AK}-1$ or $\mathrm{AK}-2$ were inoculated twice: first with either isolate

TABLE 2. Reaction of the 15 Japanese differential cultivars and japonica rice cultivar Reiho to Pyricularia grisea isolate CHNOS58-3-1 (Av-19(t))

\begin{tabular}{|c|c|c|c|}
\hline Cultivars & Resistance genotype & Lesion type $^{\mathrm{a}}$ & Reaction type ${ }^{b}$ \\
\hline Shin 2 & $P i k^{s}, P i s h^{\mathrm{c}}$ & $0-1$ & $\mathrm{R}$ \\
\hline Aichi Asahi & Pia & 1 & $\mathrm{R}$ \\
\hline Ishikari Shiroke & $P i i, P i k^{s}$ & $0-1$ & $\mathrm{R}$ \\
\hline Fujisaka 5 & $P i i, P_{i k}^{s}$ & 1 & $\mathrm{R}$ \\
\hline Kanto 51 & $P i k$ & 0 & $\mathrm{R}$ \\
\hline Kusabue & $P i k, P i s h^{\mathrm{c}}$ & 0 & $\mathrm{R}$ \\
\hline Tsuyuake & $P i k^{m}$ & 0 & $\mathrm{R}$ \\
\hline Fukunishiki & $P i z, P i s h^{\mathrm{c}}$ & $0-1$ & $\mathrm{R}$ \\
\hline Yashiro-mochi ${ }^{\mathrm{d}}$ & Pita & 1 & $\mathrm{R}$ \\
\hline $\mathrm{K} 1^{\mathrm{d}, \mathrm{e}}$ & Pita & 1 & $\mathrm{R}$ \\
\hline Pi No. $4^{\mathrm{d}}$ & $P i t a^{2}, P i s h^{\mathrm{c}}$ & 2 & $\mathrm{M}$ \\
\hline Reiho $^{d}$ & Pia, Pita ${ }^{2}$ & 5 & $\mathrm{~S}$ \\
\hline Toride $1^{\mathrm{d}}$ & $P i z^{t}, P i s h^{\mathrm{f}}$ & $0-1$ & $\mathrm{R}$ \\
\hline K60 & $P i k^{p}, P i s h^{\mathrm{f}}$ & 0 & $\mathrm{R}$ \\
\hline$B L 1^{\mathrm{d}}$ & Pib, Pish ${ }^{\mathrm{c}}$ & $0-1$ & $\mathrm{R}$ \\
\hline K59 & Pit, $P i k^{s \mathrm{f}}$ & $0-1$ & $\mathrm{R}$ \\
\hline
\end{tabular}

${ }^{a}$ Disease reaction scores are $0=$ no visible evidence of infection, $1=$ brown specks less than $0.5 \mathrm{~mm}$ in diameter, $2=$ roundish lesions less than $1 \mathrm{~mm}$ in diameter surrounded by brown margins, $3=$ small eyespot lesions less than $1.5 \mathrm{~mm}$ in diameter surrounded by dark brown margin, $4=$ intermediatesize eyespot lesions less than $2 \mathrm{~mm}$ in diameter with necrotic gray center and water-soaked or brown margins, and $5=$ large eyespot lesions more than $2 \mathrm{~mm}$ in diameter.

${ }^{\mathrm{b}} \mathrm{R}=$ resistant (scores $0-1$ ), $\mathrm{M}=$ intermediate (scores 2-3), and $\mathrm{S}=$ susceptible (scores 4-5).

${ }^{c}$ Imbe and Matsumoto (4).

d Presence of $P i k^{s}$ has not been determined.

e Presence of Pish has not been determined.

${ }^{\mathrm{f}} \mathrm{N}$. Hayashi, unpublished data.

TABLE 1. Disease reactions of isolates of Pyricularia grisea used in the study

\begin{tabular}{|c|c|c|c|c|c|c|c|c|c|c|c|c|c|c|c|c|c|}
\hline \multirow[b]{3}{*}{ Isolate } & \multirow{2}{*}{\multicolumn{10}{|c|}{ Genotype $^{a}$}} & \multicolumn{7}{|c|}{ Reaction to cultivar ${ }^{\mathrm{b}}$ (cultivar/Pi-gene ${ }^{\mathrm{c}}$ ) } \\
\hline & & & & & & & & & & & Shin 2 & $\begin{array}{l}\text { Aichi } \\
\text { Asahi }\end{array}$ & $\begin{array}{l}\text { Ishikari } \\
\text { Shiroke }\end{array}$ & Kusabue & Tsuyuake & $\begin{array}{c}\text { Yashiro- } \\
\text { mochi }\end{array}$ & Pi No. 4 \\
\hline & $A v-k s$ & $A v-s h$ & $A v-a$ & $A v-i$ & $A v-k$ & $A v-k m$ & $A v-t a$ & $A v-t a 2$ & $A v-t$ & $A v-19(t)$ & Pik ${ }^{s}$, Pish & Pia & $P i k^{s}, P i i$ & Pik, Pish & $P i k^{m}$ & Pita & Pita $^{2}$, Pish \\
\hline CHNOS58-3-1 & & & + & & & & & + & & $A v-19(t)$ & $\mathrm{R}$ & $\mathrm{R}$ & $\mathrm{R}$ & $\mathrm{R}$ & $\mathrm{R}$ & $\mathrm{R}$ & M \\
\hline PH77-89-1 & $A v-k s$ & $A v-s h$ & + & & $A v-k$ & $A v-k m$ & $A v-t a$ & $A v-t a 2$ & & + & $\mathrm{R}$ & $\mathrm{S}$ & $\mathrm{R}$ & $\mathrm{R}$ & $\mathrm{R}$ & $\mathrm{R}$ & $\mathrm{R}$ \\
\hline 3986-R-2 & $A v-k s$ & + & + & & $A v-k$ & $A v-k m$ & $A v-t a$ & $A v-t a 2$ & & + & $\mathrm{R}$ & $\mathrm{S}$ & $\mathrm{R}$ & $\mathrm{R}$ & $\mathrm{R}$ & M & $\mathrm{R}$ \\
\hline 3986-R-3 & + & $A v-s h$ & + & + & + & + & $A v-t a$ & $A v-t a 2$ & $A v-t$ & + & $\mathrm{R}$ & $\mathrm{S}$ & $\mathrm{S}$ & $\mathrm{R}$ & $\mathrm{S}$ & M & $\mathrm{R}$ \\
\hline GFOS7-1-1 & + & + & $A v-a$ & $A v-i$ & $A v-k$ & $A v-k m$ & + & + & $A v-t$ & + & $\mathrm{S}$ & $\mathrm{R}$ & $\mathrm{R}$ & $\mathrm{R}$ & $\mathrm{R}$ & $\mathrm{S}$ & $\mathrm{S}$ \\
\hline Ina72 & + & + & $A v-a$ & $A v-i$ & + & + & $A v-t a$ & $A v-t a 2$ & $A v-t$ & + & $\mathrm{S}$ & $\mathrm{R}$ & $\mathrm{R}$ & $\mathrm{S}$ & $\mathrm{S}$ & M & $\mathrm{R}$ \\
\hline Ken54-20 & + & + & + & $A v-i$ & $A v-k$ & $A v-k m$ & $A v-t a$ & $A v-t a 2$ & $A v-t$ & + & $\mathrm{S}$ & $\mathrm{S}$ & $\mathrm{R}$ & $\mathrm{R}$ & $\mathrm{R}$ & M & $\mathrm{R}$ \\
\hline GFOS8-1-1 & + & + & + & $A v-i$ & $A v-k$ & $A v-k m$ & + & + & $A v-t$ & + & $\mathrm{S}$ & $\mathrm{S}$ & $\mathrm{R}$ & $\mathrm{R}$ & $\mathrm{R}$ & $\mathrm{S}$ & $\mathrm{S}$ \\
\hline
\end{tabular}

${ }^{a}$ Avirulence/virulence gene designations according to the nomenclature of Kiyosawa (10). + is virulence gene corresponding to avirulence gene $A v$-. Blank indicates genotype unknown.

$\mathrm{b} \mathrm{R}=$ resistant, $\mathrm{M}=$ intermediate, and $\mathrm{S}=$ susceptible.

${ }^{\mathrm{c}}$ Kiyosawa (17), and Imbe and Matsumoto (4). 
Ken54-20 (Av-ta2) or CHNOS58-3-1 $(A v-19(t))$, and subsequently with either isolate CHNOS58-3-1 or Ken54-20 after the seedlings recovered from the first inoculation in order to determine the linkage relationship between the Pita $^{2}$ gene in 'Reiho' and the gene in AK lines. The population of the cross between 'Reiho' and AK-1 was further inoculated with GFOS7-1-1 $(A v-a)$ in the same way as the second inoculation.

To confirm the linkage relationship between Pit $^{2}$ and the gene in $\mathrm{AK}-1$ or $\mathrm{AK}-2$, the $\mathrm{F}_{3}$ progeny from crosses 'Reiho' $\times \mathrm{AK}-1$ or

TABLE 3. Reactions to Pyricularia grisea isolate CHNOS58-3-1 of $\mathrm{F}_{2}$ populations from crosses between rice cultivar Reiho and AK lines or 'Aichi Asahi' and from crosses between AK lines and Japanese differential cultivars

\begin{tabular}{|c|c|c|c|c|c|c|}
\hline \multirow[b]{2}{*}{ Parents or crosses ${ }^{\mathrm{a}}$} & \multicolumn{3}{|c|}{$\begin{array}{l}\text { No. of plants observed } \\
\text { for each class }{ }^{b}\end{array}$} & \multirow{2}{*}{$\begin{array}{l}\text { Expected } \\
\text { ratio } \\
\text { (R+M:S) }\end{array}$} & \multirow[b]{2}{*}{$\chi^{2}$} & \multirow[b]{2}{*}{$P^{\mathrm{c}}$} \\
\hline & $\mathrm{R}$ & M & $\mathrm{S}$ & & & \\
\hline 'Aichi Asahi' & 40 & 0 & 0 & & & \\
\hline 'Reiho' & 0 & 0 & 149 & & & \\
\hline AK-1 & 155 & 0 & 0 & & & \\
\hline AK-2 & 43 & 0 & 0 & & & \\
\hline \multicolumn{7}{|l|}{ 'Reiho' $x$} \\
\hline 'Aichi Asahi' & 760 & 0 & 275 & $3: 1$ & 1.36 & 0.24 \\
\hline AK-1 & 748 & 0 & 281 & $3: 1$ & 2.92 & 0.09 \\
\hline AK-2 & 765 & 0 & 269 & $3: 1$ & 0.57 & 0.45 \\
\hline \multicolumn{7}{|l|}{ AK-1 $x$} \\
\hline 'Aichi Asahi' & 997 & 0 & 0 & $1: 0$ & $\ldots^{\mathrm{d}}$ & $\ldots$ \\
\hline 'Shin 2' & 1,031 & 0 & 0 & $1: 0$ & $\ldots$ & $\ldots$ \\
\hline 'Ishikari Shiroke' & 965 & 0 & 0 & $1: 0$ & $\ldots$ & $\ldots$ \\
\hline 'Fujisaka 5' & 984 & 0 & 0 & 1:0 & $\ldots$ & $\ldots$ \\
\hline ‘Kusabue’ & 964 & 0 & 0 & $1: 0$ & $\ldots$ & $\ldots$ \\
\hline 'Tsuyuake'e & 81 & 0 & 0 & 1:0 & $\ldots$ & $\ldots$ \\
\hline 'Yashiro-mochi' & 982 & 0 & 0 & $1: 0$ & $\ldots$ & $\ldots$ \\
\hline 'K1' & 833 & 0 & 0 & 1:0 & $\ldots$ & $\ldots$ \\
\hline 'Pi No. 4' & 724 & 213 & 75 & $15: 1$ & 2.33 & 0.13 \\
\hline 'Toride 1' & 1,041 & 0 & 0 & $1: 0$ & $\ldots$ & $\ldots$ \\
\hline 'BL1' & 1,024 & 0 & 0 & $1: 0$ & $\ldots$ & $\ldots$ \\
\hline ‘K59’ & 1,021 & 0 & 0 & $1: 0$ & $\ldots$ & $\ldots$ \\
\hline \multicolumn{7}{|l|}{ AK-2 $x$} \\
\hline 'Kanto 51' & 1,058 & 0 & 0 & $1: 0$ & $\ldots$ & $\ldots$ \\
\hline 'Fukunishiki' & 1,015 & 0 & 0 & 1:0 & $\ldots$ & $\ldots$ \\
\hline 'K1' & 890 & 0 & 0 & $1: 0$ & $\ldots$ & $\ldots$ \\
\hline ‘K60’ & 964 & 0 & 0 & $1: 0$ & $\ldots$ & $\ldots$ \\
\hline
\end{tabular}

${ }^{a}$ Cultivars on left side in each cross were used as female parent.

${ }^{\mathrm{b}} \mathrm{R}=$ resistant, $\mathrm{M}=$ intermediate, and $\mathrm{S}=$ susceptible.

${ }^{\mathrm{c}}$ Probabilities of chi-square test for the resistant + intermediate/susceptible ratios or resistant/susceptible ratios.

${ }^{\mathrm{d}}$ Not calculated because there was no segregation of intermediate or susceptible.

e Since the $F_{2}$ generation of the cross of AK-1 $\times$ 'Tsuyuake' was sterile, a small number of $F_{2}$ plants was used for the allelism test.
AK-2 was tested. For these tests, $180 \mathrm{~F}_{2}$ plants from the cross between 'Reiho' and AK-1 and $110 \mathrm{~F}_{2}$ plants from the cross between 'Reiho' and AK-2 were selected randomly and advanced to the $\mathrm{F}_{3}$ generation. The $\mathrm{F}_{3}$ plants were separately inoculated with isolates Ken54-20 and CHNOS58-3-1. 'Reiho' was resistant to isolate Ken54-20, but susceptible to isolate CHNOS58-3-1. In contrast, AK-1 and AK-2 were resistant to isolate CHNOS58-3-1, but susceptible to isolate Ken54-20.

Statistical analysis. The segregation ratios of resistant and susceptible plants in the $\mathrm{F}_{2}$ and $\mathrm{F}_{3}$ generations were tested by the chisquare test for goodness of fit to the expected ratio.

Nomenclature. The nomenclature for the $P i$-gene was shown without a hyphen according to a report of the coordinating committee of the rice genetics cooperative (8). Avirulence gene alleles that determine virulence or avirulence on specific rice cultivars were designated according to the nomenclature of Kiyosawa (10).

\section{RESULTS}

Genetic analysis. The reactions of the $F_{1}$ hybrids between AK lines and each differential to the incompatible blast fungus isolates were identical with those of the parental cultivars resistant to the isolates. Segregations of plants resistant and susceptible to isolate CHNOS58-3-1 in the $\mathrm{F}_{2}$ population from crosses of 'Reiho' $\times$ AK-1, 'Reiho' $\times$ AK-2, and 'Reiho' $\times$ 'Aichi Asahi' showed a good fit to the expected ratio of 3:1 (resistant/susceptible) (Table 3). These results indicated that a single dominant gene confers the resistance to CHNOS58-3-1 on AK-1, AK-2, and 'Aichi Asahi'. The resistance gene in AK-1 and AK-2 is a new gene, since AK-1 and AK-2 do not carry any known resistance genes including Pia. Isolate CHNOS58-3-1 was virulent to a cultivar carrying Pia and Pita ${ }^{2}$, because cultivar Reiho, harboring Pia and Pita ${ }^{2}$ (19), was suscep-

TABLE 5. Segregation for resistance to two blast fungus isolates, Ken54-20 and CHNOS58-3-1, in the $\mathrm{F}_{3}$ families from the crosses 'Reiho' $\times$ AK lines $\left(\right.$ Pia, Pita $^{2} \times$ Pi19(t))

\begin{tabular}{lcccc}
\hline & \multicolumn{4}{c}{$\begin{array}{c}\text { Number of } \mathrm{F}_{3} \text { lines classified by reaction } \\
\text { to CHNOS58-3-1 }(A v-19(t))\end{array}$} \\
\cline { 2 - 5 } Reaction to & $\begin{array}{c}\text { Resistant } \\
\text { homo }\end{array}$ & Segregating & $\begin{array}{c}\text { Susceptible } \\
\text { homo }\end{array}$ & $\begin{array}{c}\text { Ken54-20 } \\
\text { total }\end{array}$ \\
Ken54-20 $(A v-t a 2)$ & 0 & 0 & 71 & 71 \\
Resistant homo $^{\mathrm{a}}$ & 0 & 136 & 0 & 136 \\
Segregating $_{\text {Susceptible homo }}$ & 83 & 0 & 0 & 83 \\
CHNOS58-3-1 $^{\mathrm{b}}$ & 83 & 136 & 71 & 290 \\
\hline
\end{tabular}

a All resistant.

${ }^{b}$ All susceptible.

${ }^{\mathrm{c}}$ Independent inheritance: $\chi^{2}{ }_{1: 2: 1}=2.11, \mathrm{df}=2, P>0.25$.

TABLE 4. Reaction to Pyricularia grisea isolates of $\mathrm{F}_{2}$ populations from crosses between rice cultivar Reiho and AK-1 or AK-2

\begin{tabular}{|c|c|c|c|c|c|c|c|c|c|c|c|c|c|c|c|c|}
\hline \multirow[b]{3}{*}{ Cross $\left(\mathrm{P}_{1} \times \mathrm{P}_{2}\right)$} & \multirow[b]{3}{*}{ First isolate } & \multicolumn{7}{|c|}{ Reaction to first isolate $^{a}$} & \multirow[b]{3}{*}{ Second isolate } & \multicolumn{7}{|c|}{ Reaction to second isolate } \\
\hline & & \multicolumn{2}{|c|}{ Parent } & \multicolumn{2}{|c|}{ No. of $F_{2}$ plants } & \multirow[b]{2}{*}{ Ratio } & \multirow[b]{2}{*}{$\chi^{2}$} & \multirow[b]{2}{*}{$P^{\mathrm{b}}$} & & \multicolumn{2}{|c|}{ Parent } & \multicolumn{2}{|c|}{ No. of $F_{2}$ plants } & \multirow[b]{2}{*}{ Ratio } & \multirow[b]{2}{*}{$\chi^{2}$} & \multirow[b]{2}{*}{$P$} \\
\hline & & $\mathrm{P}_{1}$ & $\mathrm{P}_{2}$ & $\mathrm{R}$ & $\mathrm{S}$ (Survived) & & & & & $\mathrm{P}_{1}$ & $\mathrm{P}_{2}$ & $\mathrm{R}$ & $\mathrm{S}$ & & & \\
\hline \multirow{5}{*}{$\begin{array}{l}\text { 'Reiho' } \times \text { AK-1 } \\
\quad\left(\text { Pia }, \text { Pita }^{2} \times \text { Pi19(t) }\right)\end{array}$} & \multirow{3}{*}{$\begin{array}{l}\text { CHNOS58-3-1 } \\
\qquad(A v-19(t))\end{array}$} & \multirow[t]{3}{*}{$\mathrm{S}$} & \multirow[t]{3}{*}{$\mathrm{R}$} & 778 & & \multirow[t]{3}{*}{$\mathrm{R}: \mathrm{S}=3: 1$} & & & & & & & & & & \\
\hline & & & & & $251(220)$ & & 0.20 & 0.65 & $\begin{array}{r}\text { Ken54-20 } \\
(A v-t a 2)\end{array}$ & $\mathrm{R}$ & $\mathrm{S}$ & 219 & 1 & & & \\
\hline & & & & & (219) & & & & $\begin{array}{l}\text { GFOS7-1-1 } \\
\quad(A v-a)\end{array}$ & $\mathrm{R}$ & $\mathrm{S}$ & 172 & 47 & $\mathrm{R}: \mathrm{S}=3: 1$ & 1.46 & 0.23 \\
\hline & \multirow{2}{*}{$\begin{array}{r}\text { Ken54-20 } \\
(A v-t a 2)\end{array}$} & \multirow[t]{2}{*}{$\mathrm{R}$} & \multirow[t]{2}{*}{$\mathrm{S}$} & \multirow[t]{2}{*}{514} & \multirow[b]{2}{*}{$158(36)$} & \multirow[t]{2}{*}{$\mathrm{R}: \mathrm{S}=3: 1$} & & & CHNOS58-3-1 & \multirow[t]{2}{*}{$\mathrm{S}$} & \multirow[t]{2}{*}{$\mathrm{R}$} & 356 & 158 & \multirow{3}{*}{$\begin{array}{l}\mathrm{R}: \mathrm{S}=3: 1 \\
\mathrm{R}_{1}: \mathrm{R}_{1,2}: \mathrm{R}_{2}=1: 2: 1^{\mathrm{d}}\end{array}$} & \multirow{2}{*}{$\begin{array}{l}9.03 \\
2.381\end{array}$} & \multirow{2}{*}{$\begin{array}{l}<0.01 \\
>0.25\end{array}$} \\
\hline & & & & & & & 0.79 & 0.37 & $\begin{array}{l}\text { CHNOS58-3-1 } \\
\quad(A v-19(t))\end{array}$ & & & 36 & 0 & & & \\
\hline $\begin{array}{l}\text { 'Reiho' } \times \text { AK-2 } \\
\quad\left(\text { Pia, } \text { Pita }^{2} \times \text { Pi19(t)) }\right.\end{array}$ & $\begin{array}{l}\text { CHNOS58-3-1 } \\
\quad(A v-19(t))\end{array}$ & $\mathrm{S}$ & $\mathrm{R}$ & 765 & $269(205)$ & $\mathrm{R}: \mathrm{S}=3: 1$ & 0.57 & 0.45 & $\begin{array}{r}\text { Ken54-20 } \\
(A v-t a 2)\end{array}$ & $\mathrm{R}$ & $\mathrm{S}$ & 205 & 0 & & & \\
\hline
\end{tabular}

${ }^{a} \mathrm{R}=$ resistant, and $\mathrm{S}=$ susceptible. "Survived" indicates susceptible plants that survived the first inoculation and were inoculated with a second or third isolate.

b Probabilities of chi-square test.

c Third isolate.

${ }^{\mathrm{d}} \mathrm{R}_{1}=$ resistant to first isolate only, $\mathrm{R}_{1,2}=$ resistant to both isolates, and $\mathrm{R}_{2}=$ resistant to second isolate. 
tible to CHNOS58-3-1 (Table 2). Therefore, the resistance gene in 'Aichi Asahi' (Pia) is also a new gene.

Results with crosses between AK lines and the 15 Japanese differentials showed that genes governing resistance to CHNOS58-3-1 in all except 'Pi No. 4' were allelic or tightly linked to the Pi-gene in the AK lines (Table 3 ). The $\mathrm{F}_{2}$ population of the cross AK-1 $\times$ 'Pi No. 4' segregated in the ratio of 12:3:1 (resistant/moderate/susceptible). These results indicated that, of the two dominant resistance genes, one showed a complete resistance and the other an intermediate resistance, and that the intermediate resistance gene derived from 'Pi No. 4' was independent of the gene in AK-1.

Linkage analysis. Almost all of the $\mathrm{F}_{2}$ plants susceptible to the first isolate CHNOS58-3-1 were resistant to the isolate Ken54-20 (Av-ta2). Only one $\mathrm{F}_{2}$ plant was susceptible to both isolates (Table $4)$. The reaction could not be confirmed in the next $F_{3}$ generation, because the susceptible $\mathrm{F}_{2}$ plant had died. In the reverse order of inoculation, all the $\mathrm{F}_{2}$ plants from the cross 'Reiho' $\times$ AK-1 susceptible to the first isolate Ken54-20 (Av-ta2) were resistant to isolate CHNOS58-3-1 ( $A v-19(t))$ (Table 4). These results strongly indicated that the $P i t a^{2}$ gene conferring resistance to the isolate Ken54-20 and the gene in AK-1 conferring resistance to the isolate CHNOS58-3-1 were not independent of each other, but linked. Segregation of resistant and susceptible plants to isolate GFOS7-1-1 $(A v-a)$ in the $\mathrm{F}_{2}$ population from the cross 'Reiho' $\times \mathrm{AK}-1$, which were susceptible to the first isolate CHNOS58-3-1, showed a good fit to the expected ratio of 3:1 (resistant/susceptible) $\left(\chi^{2}=1.46, P=\right.$ 0.23 ). These results suggested that the Pia gene, one of the two resistance genes in 'Reiho', was independent of the gene in AK-1. Segregation of resistant and susceptible plants to isolate CHNOS583-1 $(A v-19(t))$ in the $\mathrm{F}_{2}$ population from the cross 'Reiho' $\times \mathrm{AK}-1$, which were resistant to the first isolate Ken54-20 (Av-ta2), did not give a fit to the expected ratio of $3: 1$ (resistant/susceptible) $\left(\chi^{2}=\right.$ 9.03, $P<0.01$ ) (Table 4). Furthermore, assuming all 158 susceptibles to isolate Ken54-20 would have been resistant to isolate CHNOS58-3-1, the resulting 158:356:158 ratio (resistant to isolate Ken54-20 only/resistant to both isolates/resistant to isolate CHNOS58-3-1 only) in the $\mathrm{F}_{2}$ population then produced a $\chi^{2}=$ 2.381 and $P>0.25$ for a $1: 2: 1$ ratio. These results indicated that the two genes were tightly linked in the repulsion phase (Table 4).

There was no $\mathrm{F}_{3}$ line susceptible to both of the isolates Ken54-20 and CHNOS58-3-1. Resistance of the $\mathrm{F}_{3}$ plants to CHNOS58-3-1 cosegregated with susceptibility to Ken54-20 ( $A v-t a 2)$ and vice versa (Table 5).

The above-mentioned results indicated that the resistance gene to CHNOS58-3-1 is allelic or closely linked to the Pita locus. Since the gene expressed different reactions from other alleles at the Pita locus, we designated the gene in 'Aichi Asahi' and AK lines as $P i 19(t)$.

Reactions of cultivars harboring known alleles at the Pita locus. To confirm that Pi19(t) is tightly linked to Pita ${ }^{2}$, cultivars Tadukan, Pi No. 2, K1, Pi No. 4, and Yashiro-mochi carrying the resistance alleles at the Pita locus were inoculated with isolate CHNOS58-3-1 and other isolates. Among the cultivars, Tadukan
(Pita, Pita ${ }^{2}$ ) and Reiho (Pia, Pita ${ }^{2}$ ) were susceptible to isolate CHNOS58-3-1 $(A v-19(t))$, indicating that they did not carry the $P i 19(t)$ gene. 'Pi No. 4' showed type 2 lesions and did not carry the Pi19(t) gene as shown in the allelism test mentioned above. All the cultivars carrying the Pita gene except 'Tadukan' showed resistant reactions to isolates CHNOS58-3-1 and Ken54-20, lesion types 0 to 1 for isolate CHNOS58-3-1, and lesion types 1 to 2 for isolate Ken54-20 (Table 6). These results did not enable us to determine whether the resistant reaction to isolate CHNOS58-3-1 was conferred by $P i 19(t)$ or by some other unknown resistance gene.

All the additional 11 cultivars harboring the Pita gene showed lesion type 0 or 1 and were resistant to isolate CHNOS58-3-1. Among the additional 25 cultivars harboring Pit $^{2}, 15$ cultivars were resistant and 10 cultivars were susceptible to isolate CHNOS58-3-1 (data not shown).

Distribution of Pi19(t) in Japanese cultivars. All of the 17 traditional cultivars were resistant to isolate CHNOS58-3-1 (Table $7)$. Thirteen of the cultivars were expected to carry $P i k^{s}$, and five, Pish, based on the reactions to isolates 3986-R-2 and 3986-R-3. The presence of $P i 19(t)$ in the tested cultivars could not be determined when $P i k^{s}$ was detected in the cultivars, because it was not known whether or not isolate CHNOS58-3-1 carried the avirulence gene corresponding to $P i k^{s}$. When the cultivars did not carry $P i k^{s}$, the presence of Pi19(t) became clear. We confirmed that four cultivars, Gin-bouzu, Tangin-bouzu, Takenari, and Jukkoku, carried the Pi19(t) gene (Table 7). Furthermore, five cultivars that did not carry the $P i k^{s}$ gene showed type 0 to 1 lesions in reaction to isolate CHNOS58-3-1 (Table 7).

\section{DISCUSSION}

We report the presence of a new dominant gene for blast resistance in the japonica rice cultivar Aichi Asahi. Fourteen alleles at eight loci for blast resistance, viz. Pia, Pii, Pik (31), Pita (9), Pita ${ }^{2}$ (11), Piz (10), Pik (13), Pik ${ }^{p}$ (14), Pik ${ }^{h}$ (20), Piz (32), Pib, Pit (15), $P i k^{m}$ (16), and Pish (4), have been identified so far in Japanese cultivars and two foreign cultivars. The gene conferring resistance to CHNOS58-3-1 in 'Aichi Asahi' differed from any of the genes listed above and was designated as $P i 19(t)$. The Pi19(t) gene was also found in AK-1 and AK-2, which were derived from the cross between 'Aichi Asahi' and 'K59' and had never carried any known resistance genes in Japan. Allelism tests for the Pi19(t) gene with the known resistance genes in Japan showed that all differential cultivars except for 'Pi No. 4', 'Yashiro-mochi', and 'K1' carried the Pi19(t) gene, which is allelic or closely linked to the Pita locus.

Pita was identified in 'Pi No. 1' and Pita (formerly Pita2) in 'Pi No. 4', both of which were derived from 'Tadukan' $(9,11)$. When $381 \mathrm{~F}_{2}$ plants from the cross 'Pi No. 4' $\times$ 'Pi No. 1' were inoculated with Ken54-20 (Av-ta, Av-ta2), no susceptible plants were found. Though Kiyosawa (12) hesitated to decide that Pita ${ }^{2}$ is allelic to Pita, since both resistance genes originated from 'Tadukan', he tentatively concluded that Pita is allelic to Pita ${ }^{2}$ to pre-

TABLE 6. Reaction to Pyricularia grisea isolates of cultivars harboring Pita locus genes

\begin{tabular}{|c|c|c|c|c|c|c|c|}
\hline \multirow[b]{2}{*}{ Cultivar } & \multirow[b]{2}{*}{ Resistant genotype(s) } & \multicolumn{2}{|c|}{ Lesion type to } & \multicolumn{4}{|c|}{ Reaction type to ${ }^{\mathrm{a}}$} \\
\hline & & $\begin{array}{c}\text { CHNOS58-3-1 } \\
A v-19(t)\end{array}$ & $\begin{array}{c}\text { Ken54-20 } \\
A v-t a, A v-t a 2\end{array}$ & $\begin{array}{c}\text { CHNOS58-3-1 } \\
A v-19(t)\end{array}$ & $\begin{array}{c}\text { Ken54-20 } \\
A v-t a, A v-t a 2\end{array}$ & $\begin{array}{c}\text { GFOS7-1-1 } \\
A v-a\end{array}$ & $\begin{array}{c}\text { GFOS8-1-1 } \\
+\end{array}$ \\
\hline Reiho & Pia, Pita ${ }^{2}$ & 5 & 0 & $\mathrm{~S}$ & $\mathrm{R}$ & $\mathrm{R}$ & S \\
\hline Tadukan $^{\text {b }}$ & Pita, Pita ${ }^{2}$ & 4 & 0 & $\mathrm{~S}$ & $\mathrm{R}$ & $\mathrm{R}$ & M \\
\hline Pi No. 4 & Pita $^{2}$, Pish & 2 & 1 & M & $\mathrm{R}$ & $\mathrm{S}$ & $\mathrm{S}$ \\
\hline Yashiro-mochi & Pita & 1 & 2 & $\mathrm{R}$ & M & $\mathrm{S}$ & $\mathrm{S}$ \\
\hline $\mathrm{K} 1^{\mathrm{c}}$ & Pita & 1 & 2 & $\mathrm{R}$ & M & $\mathrm{S}$ & $\mathrm{S}$ \\
\hline Shimokita & Pia, Pita & $0-1$ & 1 & $\mathrm{R}$ & $\mathrm{R}$ & $\mathrm{R}$ & $\mathrm{S}$ \\
\hline Pi No. 2 & Pia, Pita & 1 & 2 & $\mathrm{R}$ & M & $\mathrm{R}$ & $\mathrm{S}$ \\
\hline
\end{tabular}

${ }^{\mathrm{a}} \mathrm{R}=$ resistant (scores 0-1); $\mathrm{M}=$ intermediate (scores 2-3); and $\mathrm{S}=$ susceptible (scores 4-5).

b Genotype is Kiyosawa's provisional conclusion (12).

c Presence of Pish has not been determined. 
vent complicating the situation. All cultivars carrying Pita, except 'Tadukan', were resistant to isolate CHNOS58-3-1 (Av-19(t)), while some of the cultivars carrying Pita $^{2}$ were susceptible to isolate CHNOS58-3-1. The relationship among Pita, Pita ${ }^{2}$, and Pi19(t) can be explained by the close linkage of Pi19(t) to the genes at the Pita locus. No susceptible recombinant to isolate CHNOS58-3-1 was obtained in $1,723 \mathrm{~F}_{2}$ plants from the cross of $\mathrm{AK}$ lines and 'K1' carrying Pita and in $982 \mathrm{~F}_{2}$ plants from the cross of AK-1 and 'Yashiro-mochi' carrying Pita. Isolate CHNOS58-3-1 (Av-19(t)) was avirulent to all the 16 cultivars carrying the Pita gene used in this study. Kiyosawa and Nomura (21) reported that the blast isolates compatible to Pita ${ }^{2}$ were always compatible to Pita, because no isolate compatible to only $P_{i t a^{2}}$ has been found among many natural isolates. According to Kiyosawa's hypothesis, isolate

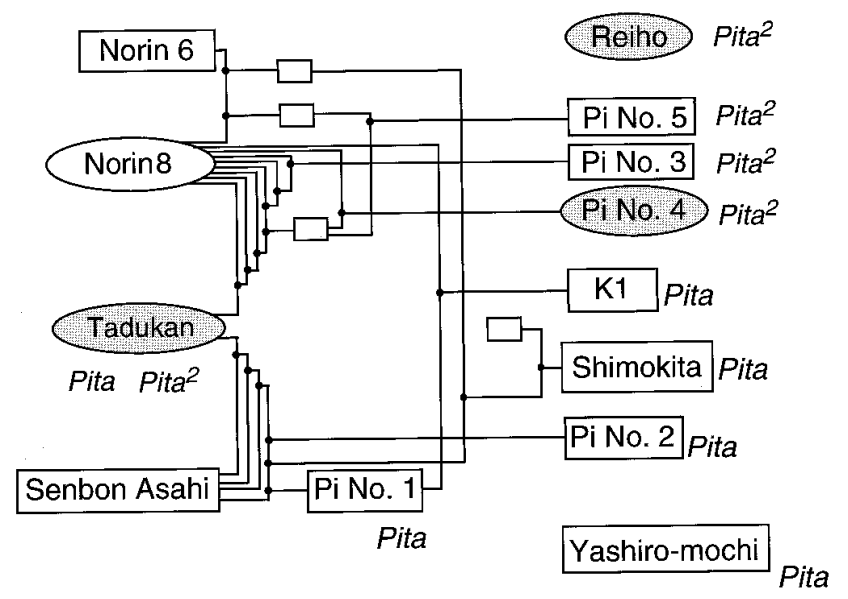

Fig. 1. Pedigree chart showing cultivars harboring genes at the Pita locus (11). All the Pita or Pita ${ }^{2}$ genes of the cultivars except for 'Yashiro-mochi' and ' $\mathrm{K} 1$ ' were derived from 'Tadukan'. 'Pi No. 4' bred from $\mathrm{F}_{1}$ between 'Tadukan' and 'Norin 8' by four backcrossings to recurrent parent 'Norin 8' does not carry Pi19(t). Shaded ellipse indicates the Pi19(t) ${ }^{+}$genotype. White ellipse indicates the Pi19(t) genotype. Square indicates that the presence of $P i 19(t)$ has not been determined.
CHNOS58-3-1 may not carry an avirulence gene corresponding to the Pita gene, because the isolate is compatible to Pita ${ }^{2}$, and as a result, 'K1' and 'Yashiro-mochi' probably carry the $P i 19(t)$ gene in addition to the Pita gene. All the cultivars carrying Pita, except 'Tadukan', showed a completely resistant reaction to isolate CHNOS58-3-1 $(A v-19(t))$ and exhibited lesion types 0 to 1 . Their reaction differed from that to Ken54-20 ( $A v-t a 2)$, lesion types 1 to 2 (Table 6). Moreover, we obtained one recombinant susceptible to both isolates CHNOS58-3-1 and Ken54-20 in the $\mathrm{F}_{2}$ population from the cross of 'Reiho' and AK-1. These results suggested that the Pi19(t) gene is closely linked to Pita and is not allelic. However, we could not confirm its susceptibility to the isolates in the next $\mathrm{F}_{3}$ generation, because the susceptible $\mathrm{F}_{2}$ plant had died. Consequently, we did not determine conclusively whether $P i 19(t)$ is allelic or tightly linked to the Pita locus.

'Pi No. 4' was bred from a cross between 'Tadukan', a Philippine indica cultivar, and 'Norin 8' backcrossed four times to the recurrent parent 'Norin 8', which possibly carried Pi19(t) (Table 7). As shown in Figure 1, Pita $^{2}$, derived from 'Tadukan', was transmitted to 'Pi No. 4' during four backcrossings. If $\mathrm{Pita}^{2}$ and Pi19(t) were independent of each other, 'Pi No. 4' should harbor the $P i 19(t)$ gene from 'Norin 8' at a high probability after four backcrosses. However, the allelism test with the $\mathrm{F}_{2}$ population from the cross between AK-1 and 'Pi No. 4' showed that 'Pi No. 4' did not harbor the Pi19(t) gene (Table 3). The results based on the pedigree analysis of the cultivars harboring an allele at the Pita locus agreed with those of linkage analysis showing that Pita $^{2}$ was allelic or tightly linked to $P i 19(t)$.

'Yashiro-mochi', 'K1', 'Pi No. 2', and 'Shimokita' carrying Pita were resistant to isolate CHNOS58-3-1. All the additional 11 cultivars carrying Pita were also resistant to the isolate. Eight of the eleven Pita genes from Japanese cultivars of the 'Yashiro-mochi' type originated from 'Pi No. 2', 'Shimokita', or 'Tadukan', based on pedigree analysis. The origin of the Pita genes of the three other cultivars was unknown. An additional 25 cultivars carrying $P i t a^{2}$ were separated into 15 cultivars resistant and 10 susceptible to the isolate. All 25 cultivars carrying Pita $^{2}$ were derived from 'Pi No. 3', 'Pi No. 4', or 'Pi No. 5', which were all bred from

TABLE 7. Reaction to Pyricularia grisea isolate CHNOS58-3-1, 3986-R-2, and 3986-R-3 of Japanese traditional rice cultivars and Japanese rice cultivars lacking Pik ${ }^{s}$

\begin{tabular}{|c|c|c|c|c|c|c|}
\hline \multirow[b]{2}{*}{ Cultivars } & \multicolumn{3}{|c|}{ Lesion type in reaction to isolates ${ }^{a}$} & \multicolumn{3}{|c|}{ Resistance genes } \\
\hline & $\begin{array}{c}\text { CHNOS58-3-1 } \\
A v-19(t) \\
\end{array}$ & $\begin{array}{c}\text { 3986-R-2 } \\
A v-19(t)^{+}, A v-k s, A v-s h^{+}\end{array}$ & $\begin{array}{c}\text { 3986-R-3 } \\
A v-19(t)^{+}, A v-k \mathrm{~s}^{+}, A v-s h\end{array}$ & $\operatorname{Pi19}(t)$ & $P i k^{s}$ & Pish \\
\hline \multicolumn{7}{|c|}{ Japanese traditional rice cultivars } \\
\hline Kamenoo & 1 & 1 & 2 & $?$ & $P i k^{s}$ & Pish \\
\hline Zuiho & 1 & 1 & 2 & $?$ & $P i k^{s}$ & Pish \\
\hline Gin-bouzu & 1 & 4 & 2 & $P i 19(t)$ & $+^{c}$ & Pish \\
\hline Kameji & 1 & 1 & 5 & $?$ & $P i k^{s}$ & + \\
\hline Sinriki & 1 & 1 & 5 & $?$ & $P i k^{s}$ & + \\
\hline Senichi & $1-2$ & $1-2$ & 5 & $?$ & $P i k^{s}$ & + \\
\hline Joushu & 1 & $0-1$ & 5 & $?$ & $P i k^{s}$ & + \\
\hline Moritawase & 2 & $1-2$ & 5 & ? & $P i k^{s}$ & + \\
\hline Asahi & 0 & 1 & 5 & ? & $P i k^{s}$ & + \\
\hline Koganemasari & 0 & 4 & 2 & $P i 19(t)$ & + & Pish \\
\hline Koshijiwase & 1 & 4 & 2 & $P i 19(t)$ & + & Pish \\
\hline Mineyutaka & $0-1$ & 4 & 5 & $P i 19(t)$ & + & + \\
\hline Nipponbare & 1 & 4 & 2 & $\operatorname{Pi19}(t)$ & + & Pish \\
\hline Norin 8 & $0-1$ & 4 & 2 & $P i 19(t)$ & + & Pish \\
\hline
\end{tabular}

${ }^{a} A v^{-}$is virulence gene corresponding to avirulence gene $A v-$.

$\mathrm{b}$ ? indicates that the presence of $P i 19(t)$ is unknown because of masking by $P i k^{s}$.

${ }^{c}+$ indicates the absence of a resistance gene. 
'Tadukan'. 'Pi No. 4' is known to carry Pish in addition to Pita (4) (Tables 1 and 2). Since isolate CHNOS58-3-1 may carry another avirulence gene corresponding to the moderate resistance based on the segregation in the $\mathrm{F}_{2}$ population of the cross between AK-1 and 'Pi No. 4' (Table 3), it is assumed that the moderate resistant reaction to isolate CHNOS58-3-1 in some cultivars harboring Pita $^{2}$ might be related to a resistance gene such as Pish. These results were also reconfirmed by pedigree analysis of the cultivars carrying Pita $^{2}$. The Pi19(t) gene seems to be present in Pita type cultivars, but not in Pita ${ }^{2}$ type cultivars, though both resistance genes Pita and Pita ${ }^{2}$ are derived from the same source, 'Tadukan' (Fig. 1). Recombination may have occurred during the crossing of 'Tadukan' with 'Norin 8'.

Since the Pita locus is located on chromosome 12 (5), Pi19(t) should also be located on chromosome 12. Furthermore, Pi4(t) (33) is also located on chromosome 12. Recently, $P i 4^{a}(t)$ has been confirmed to be identical to the Pita gene (5). Genes for resistance to other plant pathogens have often been found tightly clustered $(1,3,26-28,30)$. The results in this study suggested that the region near the Pita locus corresponds to a gene cluster.

Both Pi19(t) and Pish were identified in relation to the susceptible reaction of cultivar Reiho to blast isolates. Pish was identified in cultivars Shin 2, Kusabue, Fukunishiki, Pi No. 4, and BL1 when the resistance in 'Reiho' to local races was broken down in Kyushu in southern Japan (4). The resistance of Pi19(t) and Pish does not seem to be effective against most of the Japanese domestic blast races. In contrast, many Japanese cultivars such as Shin $2\left(\right.$ Pik $\left.^{s}, P i s h\right)$ and Sasanishiki (Pish) are resistant to most Philippines isolates (N. Hayashi, unpublished data). Inukai et al. (6) also pointed out that Japanese differentials showed a low ability to distinguish among Philippines races, suggesting that incompatibility with the Pish gene or Pi19(t) gene is widely distributed in the blast fungus population in the Philippines, but not in Japan.

The presence of Pil9(t) in Japanese cultivars including traditional cultivars could not always be determined when the cultivars were also found to carry $P_{i k}^{s}$, because the reaction of $P i 19(t)$ might be masked by the effect of the dominant gene Piks. Pi19(t) was present in all of the nine cultivars that did not carry the $P i k^{s}$ gene. Some of these cultivars had been used as breeding parents. $P i 19(t)$ was also present in almost all the Japanese differential varieties. Therefore, it was considered that $P i 19(t)$ was widely distributed in Japanese cultivars, as are Piks and Pish. For confirmation, further tests for allelism relationships between $P i 19(t)$ and the resistance gene(s) in Japanese cultivars may be required.

A set of near-isogenic lines in which all known blast resistance genes have been introduced to produce a universal differential set for classification of blast isolates is being made at the International Rice Research Institute (22). It may thus be necessary to eliminate the Pi19(t) gene from the background of the set of nearisogenic lines.

\section{ACKNOWLEDGMENTS}

We thank R. Ikeda for critically reviewing the manuscript.

\section{LITERATURE CITED}

1. Flor, H. H. 1971. Current status of the gene-for-gene concept. Adv. Genet. 8:29-54.

2. Hayashi, N., Li, C., Li, J., and Naito, H. 1997. In vitro production on rice plants of perithecia of Magnaporthe grisea isolates collected in Yunnan, China. Mycol. Res. 101:1308-1310.

3. Hulbert, S. H., and Michelmore, R. W. 1985. Linkage analysis of genes for resistance to downy mildew (Bremia lactucae) in lettuce (Lactuca sativa). Theor. Appl. Genet. 70:520-528.

4. Imbe, T., and Matsumoto, S. 1985. Inheritance of resistance of rice va- rieties to the blast fungus strains virulent to the variety "Reiho". (In Japanese.) Jpn. J. Breed. 35:332-339.

5. Inukai, T., Nelson, R. J., Zeigler, R. S., Sarkarung, S., Mackill, D. J., Bonman, J. M., Takamure, I., and Kinoshita, T. 1994. Allelism of blast resistance genes in near-isogenic lines of rice. Phytopathology 84:1278-1283.

6. Inukai, T., Nelson, R. J., Zeigler, R. S., Sarkarung, S., Takamure, I., and Kinoshita, T. 1994. Differentiation of pathogenic races of rice blast fungus by using near-isogenic lines with indica genetic background. J. Fac. Agric. Hokkaido Univ. 66:27-35.

7. Kinoshita, T., Inukai, T., and Toriyama, K. 1994. Gene symbols for blast resistance newly revised. Rice Genet. Newsl. 11:16-18.

8. Kinoshita, T., and Rothschild, G. 1995. A report of the coordinating committee of rice genetics cooperative. Rice Genet. Newsl. 12:5-6.

9. Kiyosawa, S. 1966. Studies on inheritance of resistance of rice varieties to blast 3. Inheritance of resistance of a rice variety Pi No. 1 to the blast fungus. Jpn. J. Breed. 16:243-250.

10. Kiyosawa, S. 1967. The inheritance of resistance of the Zenith type varieties of rice to the blast fungus. Jpn. J. Breed. 17:99-107.

11. Kiyosawa, S. 1967. Inheritance of resistance to the rice variety Pi No. 4 to blast. Jpn. J. Breed. 17:165-172.

12. Kiyosawa, S. 1969. The inheritance of blast-resistance in the rice variety, Yashiro-mochi. (In Japanese.) Agric. Hortic. 44:407-408.

13. Kiyosawa, S. 1969. Inheritance of resistance of rice varieties to a Philippine fungus strain of Pyricularia oryzae. Jpn. J. Breed. 19:61-73.

14. Kiyosawa, S. 1969. Inheritance of blast-resistance in west Pakistan rice variety, Pusur. Jpn. J. Breed. 19:121-128.

15. Kiyosawa, S. 1972. The inheritance of blast resistance transferred from some indica varieties in rice. Bull. Natl. Inst. Agric. Sci. D23:69-96.

16. Kiyosawa, S. 1978. Identification of blast-resistance genes in some rice varieties. Jpn. J. Breed. 28:287-296.

17. Kiyosawa, S. 1984. Establishment of differential varieties for pathogenicity test of rice blast fungus. Rice Genet. Newsl. 1:95-97.

18. Kiyosawa, S., and Ando, I. 1990. Blast resistance. Pages 361-385 in: Science of the Rice Plant. Vol. 3. T. Matsuo, ed. Nosan-gyoson Bunka Kyokai, Tokyo.

19. Kiyosawa, S., Inoue, M., and Matsumoto, N. 1978. The classification of rice blast resistance, its point of view. (In Japanese.) Plant Prot. 32:455-461.

20. Kiyosawa, S., and Murty, V. V. S. 1969. The inheritance of blast-resistance in Indian rice variety, HR-22. Jpn. J. Breed. 19:269-276.

21. Kiyosawa, S., and Nomura, K. 1988. Disease resistance in crop plants and mutation breeding. Pages 1-32 in: Mutation Breeding for Disease Resistance (Gamma Field Symposia), Vol. 27. Institute of Radiation Breeding, Ibaraki, Japan.

22. Ling, Z.-Z., Mew, T. W., Wang, J.-L., Lei, C.-L., and Huang, N. 1995. Development of near-isogenic lines as international differentials of the blast pathogen. Int. Rice Res. Note 20:13-14.

23. Mackill, D. J., and Bonman, J. M. 1992. Inheritance of blast resistance in near-isogenic lines of rice. Phytopathology 82:746-749.

24. Pan, Q., Wang, L., Ikehashi, H., and Tanisaka, T. 1996. Identification of a new blast resistance gene in the indica rice cultivar Kasalath using Japanese differential cultivars and isozyme makers. Phytopathology 86:1071-1075.

25. Rossman, A. Y., Howard, R. J., and Valent, B. 1990. Pyricularia grisea, the correct name for the rice blast disease fungus. Mycologia 82:509-512.

26. Saxena, K. M. S., and Hooker, A. L. 1968. On the structure of a gene for disease resistance in maize. Proc. Natl. Acad. Sci. U.S.A. 61:1300-1305.

27. Shepherd, K. W., and Mayo, G. M. E. 1972. Genes conferring specific plant disease resistance. Science 175:375-380.

28. Sudupak, M. A., Bennetzen, J. L., and Hulbert, S. H. 1993. Unequal exchange and meiotic instability of disease-resistance genes in the Rpl region of maize. Genetics 133:119-125.

29. Wang, G.-L., Mackill, D. J., Bonman, J. M., McCouch, S. R., Champoux, M. C., and Nelson, R. J. 1994. RFLP mapping of genes conferring complete and partial resistance to blast in a durably resistant rice cultivar. Genetics 136:1421-1434.

30. Wise, R. P., and Ellingboe, A. H. 1985. Fine structure and instability of the $M l-a$ locus in barley. Genetics 111:113-130.

31. Yamasaki, Y., and Kiyosawa, S. 1966. Studies on inheritance of resistance of rice varieties to blast 1. Inheritance of resistance of Japanese varieties to several strains of the fungus. Bull. Natl. Inst. Agric. Sci. D14:39-69.

32. Yokoo, M., and Kiyosawa, S. 1970. Inheritance of blast resistance of the rice variety, Toride1, selected from the cross Norin 8/TKM.1. Jpn. J. Breed. 20:129-132.

33. Yu, Z. H., Mackill, D. J., Bonman, J. M., and Tanksley, S. D. 1991. Tagging genes for blast resistance in rice via linkage to RFLP markers. Theor. Appl. Genet. 81:471-476. 